\title{
Características de carcaça de caprinos de cinco grupos raciais criados em confinamento ${ }^{1}$
}

\author{
Helen Fernanda Barros Gomes ${ }^{2}$, Jakilane Jacque Leal de Menezes ${ }^{3}$, Heraldo Cesar \\ Gonçalves $^{3}$, Gil Ignácio Lara Cañizares ${ }^{3}$, Brenda Batista Lemos de Medeiros ${ }^{3}$, Angelo Polizel \\ Neto $^{3}$, Raquel Vasconcelos Lourençon ${ }^{3}$, Andréia Cristina Toniolo Chávari ${ }^{3}$

\footnotetext{
${ }^{1}$ Financiado pela Fundação de Apoio à Pesquisa do Estado de São Paulo.

2 Instituto de Ciências Agrárias e Ambientais/UFMT, Sinop - MT.

${ }^{3}$ Faculdade de Medicina Veterinária e Zootecnia/UNESP, Botucatu - SP.
}

RESUMO - Este trabalho foi realizado com o objetivo de avaliar a influência do grupo racial e da condição sexual nas características da carcaça de caprinos jovens criados em confinamento. Foram utilizados 91 animais, 52 machos e 39 fêmeas, pertencentes a cinco grupos raciais: Alpino, 1/2Boer + 1/2Alpino, $1 / 2$ Anglo Nubiano $+1 / 2$ Alpino, 3/4Boer $+1 / 4$ Alpino, e 1/2Anglo Nubiano $+1 / 4$ Boer $+1 / 4$ Alpino. Foi tomado o peso ao jejum, no dia do abate, após 24 horas de jejum de sólidos. Foram tomadas medidas biométricas e de carcaça, objetiva e subjetivamente. O grupo racial influenciou a altura de cernelha, o comprimento interno e externo da carcaça e o comprimento de perna, que foram maiores nos animais Alpinos, bem como a largura do peito, o escore corporal, os índices de compacidade da carcaça e da perna e a cobertura de gordura da carcaça, que foram melhores nos animais com grau de sangue Boer. Animais machos tiveram maior altura de cernelha, medidas da estérnebra com ultrassom, comprimento interno da carcaça, comprimento de perna, profundidade dos tecidos na altura da 33 e $44^{\mathrm{a}}$ estérnebras tomadas na carcaça. Nas demais características corporais avaliadas, não foram encontradas diferenças entre grupos raciais e sexo dos animais. O cruzamento do grupo Boer com Alpino reduz o comprimento das carcaças e aumenta a cobertura de gordura e a quantidade de tecidos depositados, mas não influencia o desempenho do animal.

Palavras chave: cabritos, conformação, grupo genético, raça, rendimento

\section{Carcass traits of characteristics of kid goats from five breed groups raised in a feedlot system}

\begin{abstract}
This study was carried out with the objective of evaluating the influence of breed groups and sexual conditional on carcass traits of young goats raised in feedlot. It was used 91 animals, 52 males and 39 females, belonging to five breed groups: Alpine, $1 / 2$ Boer $+1 / 2$ Alpine, $1 / 2$ Nubian $+1 / 2$ Alpine, $3 / 4$ Boer $+1 / 4$ Alpine and $1 / 2$ Anglo-Nubian $+1 / 4$ Boer $+1 / 4$ Alpine On the slaughter day, the shrunk weight was measured after 24 hours of solid fasting. Biometric and carcass measures were objectively and subjectively taken. Racial group influenced withers, internal and external carcass length, and leg length, which were greater for Alpine animals, as well as chest width, body condition score, carcass and leg compactness index and fat thickness on carcass, which were better in animals with Boer blood degree. Male animals showed greater withers, measures of sternebrae by ultrasound, internal carcass length, leg length, tissue depth height between $3^{\text {rd }}$ and $4^{\text {th }}$ sternebrae measured on carcass. On the other body evaluated characteristics, it was not found any differences among breed groups and sex of the animals. Crossing Boer with Alpine reduces carcass length, and increases fat thickness and deposited tissue, however, it does not change animal performance.
\end{abstract}

Key Words: breed, conformation, genetic group, kid goats, yield

\section{Introdução}

A procura nacional por carnes com baixo teor de gordura tem estimulado a criação de caprinos de corte, uma vez que a carne caprina contém proteína e ferro em quantidades semelhantes a de outras carnes vermelhas de ruminantes, além de reduzido teor de gordura saturada e colesterol (Malan, 2000). Além disso, no processo de evisceração, a maior parte da gordura é extraída, pois em caprinos $45 \%$ da gordura corporal está armazenada nas vísceras (Potchoiba et al., 1990).

Para atender a esse novo nicho de mercado, produtores de leite têm destinado parte de suas matrizes para acasalamento com machos de raças de corte, como a Boer, que apresenta características desejáveis de desempenho e carcaça, e a Anglo-Nubiana, raça de aptidão mista, com boa disponibilidade no mercado e a preços acessíveis. 
Como a qualidade da carcaça não depende apenas do peso, mas também de outras características, como teor de gordura, composição muscular e conformação (Ávila, 1995), que podem sofrer influência do sexo, do grupo racial, da idade e do sistema de criação do animal, realizou-se este estudo com o objetivo de avaliar os efeitos do grupo racial e da condição sexual no desempenho e nas características da carcaça de caprinos jovens criados em confinamento.

\section{Material e Métodos}

O experimento foi realizado na área de produção de caprinos da Faculdade de Medicina Veterinária e Zootecnia/ FMVZ - UNESP, em Botucatu-SP. Os caprinos utilizados foram gerados de cabras Alpinas e mestiças $1 / 2$ Boer $+1 / 2$ Alpina, acasaladas a partir de março de 2006 e mantidas confinadas em baias coletivas $\left(1,5 \mathrm{~m}^{2} /\right.$ animal $)$ com piso ripado e livre acesso a solário com piso de concreto.

As cabras Alpinas foram divididas aleatoriamente em três lotes e acasaladas com bodes das raças: Alpina, Boer e Anglo-Nubiana, para produção de caprinos de três grupos raciais: Alpino (A); $1 / 2$ Boer + $1 / 2$ Alpino ( $1 / 2 \mathrm{BA}) ; \mathrm{e}^{1 / 2}$ AngloNubiano + $1 / 2$ Alpino ( $1 / 2$ ANA). As cabras $1 / 2$ Boer $+1 / 2$ Alpina foram acasaladas, seguindo o mesmo procedimento, com bodes Boer e Anglo-Nubianos para produção dos grupos raciais: $3 / 4$ Boer + 1/4 Alpino (3/4 BA) e $1 / 2$ Anglo-Nubiano + 1/4 Boer $+1 / 4$ Alpino - Three cross (Tabela 1 ).

Os cabritos nasceram em agosto e setembro de 2006 e, ao nascer, foram separados das mães, pesados, identificados com coleiras, receberam tratamento do cordão umbilical e foram alojados em dez baias coletivas de acordo com o sexo e o grupo racial. As baias coletivas apresentavam dimensão de 2,0 $\times 3,0 \mathrm{~m}$, com piso ripado elevado do solo e providas de bebedouros automáticos de fibra de vidro.

A alimentação foi composta de colostro, fornecido em mamadeira durante os três primeiros dias de vida. Posteriormente, o aleitamento foi feito em calhas de PVC com fornecimento máximo de 1,5 L/animal/dia de leite de cabra e, ou, de vaca, em duas frequências diárias até dez dias e depois apenas uma até o desaleitamento aos 60 dias.

Até 30 dias de idade, foi fornecido aos animais, à vontade, feno de aveia e, a partir dessa idade, foi fornecida dieta completa em péletes contendo $30 \%$ feno de aveia e $70 \%$ de concentrado, composta de: $49 \%$ de milho, $38 \%$ de farelo de soja, $10 \%$ de farelo de algodão, $2 \%$ de calcário e $1 \%$ de sal mineral. A dieta foi constituída de $90,54 \%$ de MS, $19,25 \%$ de PB, 3,87\% de extrato etéreo e $31,25 \%$ de FDN.

No dia anterior ao abate, foram tomadas medidas biométricas: altura na cernelha; largura do peito, com auxílio de um paquímetro; escore de condição corporal, variando de 0 (muito magro) a 5 (extremamente gordo), avaliado subjetivamente por palpação na região lombar. Também foram colhidas imagens de ultrassom, coletadas na região dorsal sobre o longissimus dorsi, no lado esquerdo, entre a 12 a e a 13 a costelas, e na região esternal entre a $3 \underline{a}$ e a 4 a estérnebras, para avaliação da profundidade do lombo e dos tecidos esternais, compreendendo gordura, músculo e osso, respectivamente. O equipamento utilizado foi o Piemedical Scanneer 200 vet tempo real com transdutor 5,0 MHz, próprio para caprinos.

Os animais foram abatidos com idade média de 110 dias (variando de 63 a 119 dias), sob inspeção estadual, seguindo a rotina normal do abatedouro, situado a $25 \mathrm{~km}$ do local do experimento. Anterior ao embarque para o abatedouro, os animais foram submetidos a jejum de sólidos de 24 horas para determinação do peso vivo em jejum.

Após insensibilização por contusão, sangria, esfola e evisceração, as carcaças foram identificadas com lacres numerados no tendão-de-aquiles e imediatamente pesadas para obtenção do peso da carcaça quente. Após refrigeração em câmara fria por 24 horas a $4^{\circ} \mathrm{C}$, foram novamente pesadas para determinação do peso da carcaça fria.

Com base nos pesos de carcaça, foram calculados a perda ao resfriamento, pela diferença entre o peso de carcaça quente e o peso de carcaça fria; e o rendimento comercial da carcaça, pela relação entre o peso da carcaça fria e o peso em jejum.

Após o resfriamento, as carcaças foram transportadas em carro não refrigerado para o laboratório, onde foram realizadas as avaliações das características de carcaça.

As carcaças foram avaliadas subjetivamente, com notas de 1 a 5, quanto à conformação, em que 1 representa pouca e 5 adequada deposição muscular na carcaça; e quanto à cobertura de gordura da carcaça, em que 1 representa pouca

Tabela 1 - Distribuição dos animais experimentais de acordo com o grupo racial e o sexo

\begin{tabular}{lcccccc}
\hline & \multicolumn{5}{c}{ Grupo racial ${ }^{1}$} \\
\cline { 2 - 7 } Sexo & Alpinos & $1 / 2$ Boer $+1 / 2$ Alpino & $1 / 2$ Anglo-Nubiano $+1 / 2$ Alpino & $3 / 4$ Boer $+1 / 4$ Alpino & Three cross & Total \\
\hline Macho & 11 & 7 & 11 & 12 & 11 \\
Fêmea & 4 & 12 & 9 & 8 & 52 \\
Total & 15 & 19 & 20 & 20 & 39 & 17 \\
\hline
\end{tabular}


ou insignificante e 5 boa ou adequada deposição de gordura de cobertura. Também foi avaliada objetivamente segundo metodologia de Sañudo \& Sierra (1986), com o auxílio de uma fita métrica em: comprimento interno e externo da carcaça, perímetro do tórax, perímetro da perna, perímetro da garupa, largura do peito, comprimento da perna, e largura da garupa. Com uma régua milimétrica, foi tomada a espessura dos tecidos (osso + músculo + gordura) da $3 \underline{a}$ e da $4 \underline{a}$ estérnebras.

Os pontos limites das medidas supracitadas foram: CIC - distância entre o bordo anterior do osso púbis e o bordo anterior da primeira costela em seu ponto médio; CEC distância entre a articulação cervico-torácica e a primeira articulação intercoccígea; PT - perímetro medido atrás da paleta; $\mathrm{PP}$ - perímetro tomado com base à parte média da perna, acima da articulação fêmuro-tíbio-rotuliana; PG perímetro na região da garupa, com base nos trocânteres do fêmur; $\mathrm{LP}$ - largura máxima do tórax; $\mathrm{CP}$ - distância entre o trocânter maior do fêmur e o bordo da articulação tarsometatarsiana; e LG - largura máxima entre os trocânteres dos fêmures.

Foram calculados os índices de compacidade da carcaça (ICC), pela relação entre o peso da carcaça fria e o comprimento interno da carcaça (PCF/CIC); e o índice de compacidade da perna (ICP), pela relação entre a largura da garupa e o comprimento da perna (LG/CP).

As variáveis foram avaliadas em delineamento inteiramente casualizado com arranjo fatorial de cinco grupos raciais e duas condições sexuais $(5 \times 2)$, considerando o peso em jejum (PJ) como covariável. Também foram desenvolvidas equações de regressão a partir das medidas observadas no animal vivo e após o abate, para predizer as variáveis estudadas em relação ao peso em jejum.

As análises de variância e o teste de Tukey $(\mathrm{P}<0,05)$ foram processados pelo programa estatístico SAEG (UFV, 2000), utilizando-se o modelo:

$$
\mathrm{Y}_{\mathrm{ijk}}=\mu+\mathrm{GR}_{\mathrm{i}}+\mathrm{S}_{\mathrm{j}}+\mathrm{GR} * \mathrm{~S}_{\mathrm{ij}}+\mathrm{b}\left(\mathrm{X}_{\mathrm{ijK}}-\bar{X}\right)+\mathrm{e}_{\mathrm{ijk}} \text {, }
$$
em que: $\mathrm{Y}_{\mathrm{ijk}}=$ características avaliadas no animal $\mathrm{k}$, do sexo $\mathrm{j}$ e grupo racial $\mathrm{i} ; \mu=$ constante inerente aos dados; $\mathrm{GR}_{\mathrm{i}}=$ efeito do grupo racial $i$, em que $i=1: A, 2: 1 / 2 \mathrm{BA}, 3: 1 / 2 \mathrm{ANA}$, 4: $3 / 4$ BA e $5:$ TC; $S_{j}=$ efeito do sexo $\mathrm{j}$, em que $\mathrm{j}=1$ : macho e 2: fêmea; $G R * \mathrm{~S}_{\mathrm{IJ}}=$ efeito da interação entre o grupo racial i e o sexoj; b = coeficiente de regressão linear da característica em função do peso jejum (PJ); $\mathrm{X}_{\mathrm{ijK}}=$ peso jejum do animal $\mathrm{k}$ do sexo j e grupo racial $\mathrm{i} ; X^{-}=$média do peso em jejum; $\mathrm{e}_{\mathrm{ijk}}=$ erro aleatório referente à observação $\mathrm{Y}_{\mathrm{ijk}}, \mathrm{NID},\left(0, \sigma_{e}^{2}\right)$.

\section{Resultados e Discussão}

O grupo racial teve efeito significativo na largura do peito, na altura de cernelha, no escore corporal e na medida de estérnebra tomada com ultrassom. A largura da maçã do peito nos mestiços Boer e Three Cross foi maior que nos Alpinos e estes não diferiram dos $1 / 2$ ANA. Os Alpinos e os $1 / 2$ ANA tiveram maior altura de cernelha em comparação aos $3 / 4$ BA e Three Cross, enquanto os $1 / 2$ BA ficaram em situação intermediária. Os $3 / 4 \mathrm{BA}$ apresentaram melhor escore corporal em comparação aos Three Cross e $1 / 2$ ANA e estes foram melhores que os Alpinos, enquanto os $1 / 2 \mathrm{BA}$ ficaram em posição intermediária entre $3 / 4 \mathrm{BA}$, os Three Cross e os $1 / 2$ ANA. A medida da estérnebra com ultrassom foi maior nos $3 / 4$ BA que nos $1 / 2$ ANA, e as demais comparações entre os grupos raciais não mostraram diferenças.

Entre os sexos, houve diferenças para as características altura de cernelha, escore corporal e medidas de estérnebra com ultrassom, sendo que os valores encontrados para altura de cernelha e estérnebra foram maiores nos machos, e o escore corporal maior para as fêmeas (Tabela 2).

A avaliação conjunta das medidas biométricas evidenciou a existência de diferenças corporais entre os grupos raciais, uma vez que não foi observada diferença no peso em jejum, que apresentou valor médio de $18,77 \mathrm{~kg}$. Maiores alturas foram observadas nos animais com maior grau de sangue Alpino e Anglo-Nubiano, que, por isso, apresentaram menor escore corporal, medidas de estérnebra e menores larguras do peito, indicando menos tecidos

Tabela 2 - Média estimada dos dados de desempenho e medidas biométricas de caprinos de cinco grupos raciais criados em confinamento

\begin{tabular}{|c|c|c|c|c|c|c|c|c|}
\hline Característica $^{1}$ & Média & \multicolumn{4}{|c|}{ Grupo racial $^{2}$} & $\mathrm{TC}$ & \multicolumn{2}{|c|}{ Sexo } \\
\hline Largura do peito $(\mathrm{cm})$ & 4,66 & $4,23 b$ & $4,78 \mathrm{a}$ & $4,61 \mathrm{ab}$ & $4,88 \mathrm{a}$ & $4,79 \mathrm{a}$ & 4,67 & 4,65 \\
\hline Escore de condição corporal $(0-5)$ & 3,00 & $2,59 \mathrm{c}$ & $3,15 \mathrm{ab}$ & $2,92 b$ & $3,31 \mathrm{a}$ & $3,02 b$ & $2,94 b$ & $3,06 \mathrm{a}$ \\
\hline EST-US (cm) & 1,989 & $1,962 \mathrm{ab}$ & $2,022 \mathrm{ab}$ & $1,873 b$ & $2,051 \mathrm{a}$ & $2,038 \mathrm{ab}$ & $2,033 \mathrm{a}$ & $1,945 b$ \\
\hline PF LOMBO-US (cm) & 1,869 & $1,809 \mathrm{a}$ & $1,931 \mathrm{a}$ & $1,799 \mathrm{a}$ & $1,924 \mathrm{a}$ & $1,884 \mathrm{a}$ & 1,855 & 1,884 \\
\hline
\end{tabular}

Médias seguidas de mesma letra nas linhas não diferem entre si $(\mathrm{P}>0,05)$ pelo teste Tukey.

${ }^{1}$ EST-US = profundidade dos tecidos entre $3 \underline{a}$ e $4 \underline{a}$ estérnebras medidas com ultrassom; PF LOMBO-US = profundidade do lombo entre a $12^{\underline{a}}$ e $13 \underline{a}$ costelas medido com ultrassom.

${ }^{2}$ A - Alpino, $1 / 2$ BA - Boer $\times$ Alpino, $1 / 2$ ANA - Anglo-Nubiano $\times$ Alpino, $3 / 4$ BA $-1 / 2$ BA $\times$ Boer, TC $-1 / 2$ BA $\times$ Anglo-Nubiano. 
corporais por unidade de comprimento e com menor largura dos músculos (profundidade do lombo tomada com ultrassom).

Esses resultados são concordantes com os de Dhanda et al. (1999), que também observaram nos animais Alpinos estrutura corporal mais alta e longilínea, possivelmente por serem animais leiteiros cuja seleção leva a redução da massa muscular; e com Van Niekerk \& Casey (1988), que, em estudo com animais Bôer, confirmaram seu potencial para produção de carcaças e carne de qualidade, o que concorda com o observado por Menezes (2005). De acordo com Standfort et al. (1995), raças voltadas para produção de carne apresentam melhor conformação de carcaça pelo desenvolvimento de massas musculares e adequada quantidade e distribuição de gordura de cobertura.

Entre os grupos raciais, o comprimento interno da carcaça foi maior nos Alpinos e $1 / 2$ ANA, intermediário nos $1 / 2$ BA e Three Cross e menor para os $3 / 4$ BA. Da mesma forma, para o comprimento externo da carcaça, os Alpinos apresentaram maior valor do que os $1 / 2$ ANA e Three Cross, que foram semelhantes entre si e que, por sua vez, maiores que os Three Cross e $1 / 2 \mathrm{BA}$, que não diferiram entre si, enquanto os $3 / 4$ BA apresentaram menor valor (Tabela 3 ).

Uma das características desejáveis e selecionadas em animais leiteiros é o comprimento corporal, que pode ter influenciado o maior comprimento interno e externo da carcaça dos Alpinos em relação aos mestiços Boer, que foram mais compactos. Esses resultados confirmam observações de Skinner (1972), em animais cruzados Boer, e de Menezes (2005), em grupamentos idênticos ao deste estudo.
Os resultados de cobertura de gordura foram melhores para os mestiços Boer $\times$ Alpino que para os Alpinos e não diferiram entre os $1 / 2$ ANA e Three Cross. O comprimento da perna foi maior para os Alpinos e $1 / 2$ ANA, intermediários para os $1 / 2$ BA e Three Cross seguidos dos $3 / 4$ BA, devido ao biotipo funcional leiteiro dos Alpinos e Anglo-Nubianos (Tabela 3).

Os machos tiveram maior comprimento interno da carcaça, maior comprimento da perna e medidas da $3 \underline{a}$ e $4^{a}$ estérnebra em relação às fêmeas, o que pode, em parte, ser explicado pelo maior potencial de crescimento muscular dos machos em relação às fêmeas e por essas serem medidas que consideram não apenas a deposição de gordura naquela região, mas a quantidade total dos tecidos, evidenciando a precocidade dos machos em deposição tecidual na carcaça.

O observado neste experimento foi similar ao reportado por Pires et al. (1999) que não observaram diferença de pesos de carcaça entre as diferentes condições sexuais de cordeiros mestiços Texel confinados, em que machos nãocastrados, castrados e fêmeas apresentaram valores semelhantes para peso da carcaça quente e fria, perda ao resfriamento, espessura de gordura subcutânea e rendimento.

Em geral, a proporção de gordura é menor nos machos não-castrados e maior nas fêmeas (Deambrosis, 1972) e isso ocorre em virtude do grau de maturidade e da ação do hormônio masculino (testosterona), que promove o crescimento muscular e esquelético determinando carcaças mais magras (Jacobs et al., 1972). Apesar disso, não foi observada diferença entre sexos neste experimento, o que pode ser justificado pela alimentação adequada dos animais

Tabela 3 - Características de carcaça de caprinos de cinco grupos raciais criados em confinamento

\begin{tabular}{|c|c|c|c|c|c|c|c|c|}
\hline \multirow[b]{2}{*}{ Característica } & \multirow[b]{2}{*}{ Média } & \multicolumn{5}{|c|}{ Grupo racial ${ }^{1}$} & \multicolumn{2}{|c|}{ Sexo } \\
\hline & & A & $1 / 2 \mathrm{BA}$ & $1 / 2$ ANA & $3 / 4 \mathrm{BA}$ & $\mathrm{TC}$ & Macho & Fêmea \\
\hline Peso de carcaça quente $(\mathrm{kg})$ & 8,33 & 8,21 & 8,33 & 8,25 & 8,41 & 8,47 & 8,42 & 8,25 \\
\hline Perda ao resfriamento $(\%)$ & 6,24 & 6,98 & 6,28 & 6,11 & 6,42 & 5,40 & 6,41 & 6,07 \\
\hline Comprimento interno da carcaça $(\mathrm{cm})$ & 43,93 & $46,04 \mathrm{a}$ & $43,18 b$ & $45,32 \mathrm{a}$ & $41,16 \mathrm{c}$ & $43,94 b$ & $44,25 \mathrm{a}$ & $43,60 \mathrm{~b}$ \\
\hline Comprimento externo da carcaça $(\mathrm{cm})$ & 48,34 & $52,24 \mathrm{a}$ & $47,31 \mathrm{c}$ & $48,80 \mathrm{~b}$ & $45,31 \mathrm{~d}$ & $48,04 \mathrm{bc}$ & 48,31 & 48,37 \\
\hline Perímetro do tórax $(\mathrm{cm})$ & 56,51 & 57,67 & 56,34 & 56,97 & 55,51 & 56,06 & 56,63 & 56,39 \\
\hline Perímetro da perna $(\mathrm{cm})$ & 27,98 & 28,19 & 28,54 & 28,25 & 26,99 & 27,94 & 28,18 & 27,79 \\
\hline Comprimento da perna $(\mathrm{cm})$ & 28,56 & $30,77 \mathrm{a}$ & $27,78 b$ & $29,82 \mathrm{a}$ & $26,06 \mathrm{c}$ & $28,38 b$ & $28,89 \mathrm{a}$ & $28,23 b$ \\
\hline Perímetro da garupa $(\mathrm{cm})$ & 37,81 & 37,39 & 38,52 & 37,04 & 36,78 & 39,30 & 37,97 & 37,64 \\
\hline Largura da garupa $(\mathrm{cm})$ & 13,64 & 13,53 & 13,75 & 13,40 & 13,60 & 13,91 & 13,75 & 13,52 \\
\hline Largura do peito $(\mathrm{cm})$ & 19,81 & 19,18 & 19,92 & 19,50 & 20,96 & 19,48 & 19,40 & 20,22 \\
\hline
\end{tabular}

Médias seguidas de letras diferentes nas linhas, na mesma fonte de variação, diferem entre si $(\mathrm{P}<0,05)$ pelo teste Tukey.

${ }^{1} \mathrm{~A}-$ Alpino; $1 / 2$ BA - Boer $\times$ Alpino; $1 / 2$ ANA - Anglo-Nubiano $\times$ Alpino; $3 / 4$ BA $-1 / 2$ BA $\times$ Boer; TC $-1 / 2$ BA $\times$ Anglo-Nubiano. 
em confinamento e pelo abate precoce, como observado por Pires et al. (1999), que encontraram resultados semelhantes para cordeiros confinados abatidos aos 100 dias de idade.

A média de perda por resfriamento foi de $6,24 \%$, valor condizente com o de 5,88\% observado por Menezes (2005) em carcaças de caprinos de quatro grupos genéticos em sistema de criação similar. Esse valor pode ser considerado alto se comparado ao de 3,04\% relatado por Pires et al. (1999) para cordeiros e pode ser em consequência da reduzida espessura da gordura de cobertura que protege a carcaça do ressecamento pelo frio dos caprinos. De acordo com Bonifacino et al. (1979) e Lloyd et al. (1983), a perda ao resfriamento varia de 3 a $4 \%$ entre animais puros e mestiços. Todavia, Siqueira \& Fernandes (1999) constataram que, tanto os pesos médios da carcaça quente e fria quanto as perdas por resfriamento, foram similares entre cordeiros puros $(3,54 \%)$ e mestiços $(2,83 \%)$, o que também foi observado nesta pesquisa com caprinos.

O índice de compacidade da carcaça foi maior nos mestiços Boer e Three Cross em relação aos 1/2 ANA e Alpinos, enquanto o índice do compacidade da perna foi melhor nos mestiços Boer em relação aos Alpinos e $1 / 2$ ANA. Os Three Cross não diferiram dos mestiços Boer e dos $1 / 2$ ANA, mas também foram superiores aos Alpinos (Tabela 4). O índice de compacidade da carcaça pode ser utilizado para avaliar a produção de tecidos na carcaça de animais com peso vivo semelhante (Simela et al., 1999) e, quanto maiores os valores encontrados para o índice de compacidade da carcaça, maior a proporção de músculo e gordura na carcaça do animal (Osório, 1992).

Segundo Yañes et al. (2004), as medidas da garupa e da perna na carcaça podem ser utilizadas como indicativo da conformação e da musculosidade, apesar da ausência de pesquisas correlacionando essas medidas com a composição tecidual e/ou participação proporcional dessa região na carcaça de caprinos.

A raça Boer, logo na primeira geração de cruzamento com a raça Alpina, aumentou a quantidade de tecido na carcaça, o que não ocorreu com a Anglo-Nubiana. Como os animais $3 / 4$ BA e Three Cross não diferiram quanto aos índices avaliados, o uso de reprodutores Boer ou AngloNubianos em cabras $1 / 2$ BA pode ser recomendado.

De modo geral, o cruzamento dos grupos Boer e Alpino reduziu o comprimento das carcaças, aumentou a cobertura de gordura e a quantidade de tecidos depositados na carcaça logo na primeira prole. Já no cruzamento AngloNubiano $\times$ Alpinas, isso foi possível apenas quando foram utilizadas fêmeas $1 / 2$ Boer $+1 / 2$ Alpinas.

O rendimento comercial da carcaça não foi influenciado pelo grupo racial, tampouco pela condição sexual (Tabela 4), discordando de observações de Pelle et al. (1987) e Frederiksen (1991), que encontraram maiores rendimentos nos mestiços em relação aos animais puros. A média de $41,7 \%$ no rendimento comercial da carcaça está dentro dos limites recomendados para caprinos, com valores de 38 a 51\% (El Khidir et al., 1998; Bueno et al., 1999).

De acordo com Madruga (1999), o rendimento pode aumentar com o peso vivo do animal. Em estudos com animais da raça Saanen, foram encontrados valores de $43,7 \%$ para animais abatidos aos $20 \mathrm{~kg}$ e de $47,3 \%$ para animais abatidos com $35 \mathrm{~kg}$ de peso vivo (Yañes, 2002). Esses autores comentaram que raças voltadas para a produção de carne apresentam melhor conformação de carcaça pelo desenvolvimento, perfil de massas musculares e adequada quantidade e distribuição de gordura de cobertura.

Esses resultados mostram que os grupos raciais apresentaram potencial para crescimento semelhante e mostraram-se bem adaptados ao sistema de aleitamento artificial a que foram submetidos.

A utilização da raça Boer e Anglo-Nubiana em cruzamentos com fêmeas Alpinas ou mestiças Boer + Alpina produziu cabritos com desempenho semelhante, indicando que qualquer uma das raças pode ser utilizada em cruzamentos e que a escolha depende daquela que apresente menor custo para aquisição de reprodutores.

Não foram encontradas diferenças para as demais variáveis avaliadas, e isso indica que, em iguais condições de nutrição, os grupos raciais estudados podem apresentar valores semelhantes de peso e desempenho; concordando com os dados de Goonewardene et al. (1998) e Menezes (2005).

Tabela 4 - Índices de rendimento da carcaça em caprinos de cinco grupos raciais criados em confinamento

\begin{tabular}{|c|c|c|c|c|c|c|c|c|}
\hline \multirow[b]{2}{*}{ Característica } & \multirow[b]{2}{*}{ Média } & \multicolumn{5}{|c|}{ Grupo racial $^{1}$} & \multicolumn{2}{|c|}{ Sexo } \\
\hline & & A & $1 / 2 \mathrm{BA}$ & $1 / 2$ ANA & $3 / 4 \mathrm{BA}$ & $\mathrm{TC}$ & Macho & Fêmea \\
\hline Índice de compacidade da carcaça & 0,18 & $0,16 \mathrm{~b}$ & $0,18 \mathrm{a}$ & $0,17 b$ & $0,19 \mathrm{a}$ & $0,18 \mathrm{a}$ & 0,18 & 0,18 \\
\hline Rendimento comercial da carcaça & 0,42 & 0,40 & 0,41 & 0,41 & 0,42 & 0,47 & 0,42 & 0,41 \\
\hline
\end{tabular}

Médias seguidas de letras diferentes na mesma linha diferem entre si $(\mathrm{P}<0,05)$ pelo teste Tukey.

${ }^{1} \mathrm{~A}-$ Alpino; $1 / 2 \mathrm{BA}-$ Boer $\times$ Alpino; $1 / 2$ ANA - Anglo-Nubiano $\times$ Alpino; 3/4 BA - 1/2 BA $\times$ Boer; TC $-1 / 2$ BA $\times$ Anglo-Nubiano. 
A partir das medidas observadas no animal vivo e na carcaça de todos os animais, foram estimadas equações de regressão para predizer as variáveis estudadas em função do peso em jejum. O peso da carcaça quente e fria, o comprimento interno e externo da carcaça, a conformação, a cobertura de gordura, o perímetro e a largura da garupa aumentaram linearmente de acordo com o peso em jejum (Tabela 5), o que era esperado, já que são características relativas à dimensão e conformação da carcaça.

$\mathrm{O}$ rendimento comercial da carcaça pode ser muito variável, pois é influenciado por fatores como raça, idade, peso de abate, sexo (Yañes, 2002) e sistema de criação. Neste estudo o rendimento comercial da carcaça não foi afetado pelo peso em jejum, discordando dos dados de Madruga (1999) e de Yañes (2002), que afirmam haver relação direta entre rendimento comercial da carcaça e peso emjejum.

O peso da carcaça quente e fria aumentou linearmente com o peso em jejum dos animais. Para cada unidade de ganho no peso em jejum, os animais ganharam $0,44 \mathrm{e} 0,41 \mathrm{~kg}$ no peso da carcaça quente e fria, respectivamente. Da mesma forma, as demais equações expressam aumento linear em relação ao peso em jejum, e o aumento observado para cada unidade do peso em jejum foi de $0,53 \mathrm{e} 0,70 \mathrm{~cm}$ para o comprimento interno e externo da carcaça; já para os valores subjetivos foi de 0,032 e 0,075 ponto para cobertura de gordura e conformação da carcaça, respectivamente.
Cada quilo de aumento no peso em jejum representou acréscimo de 0,40 e $0,16 \mathrm{~cm}$ nas medidas perímetro e largura da garupa, respectivamente.

Apesar de terem sido significativas, as equações lineares para as características avaliadas subjetivamente (conformação e cobertura de gordura da carcaça) apresentaram coeficiente de determinação muito baixo e o mesmo aconteceu para perímetro e largura da garupa, comprovando pequena adequação da equação aos dados.

Para as medidas de perímetro do tórax, perímetro da perna e largura da perna, as equações quadráticas foram mais ajustadas (Tabela 5). Pela derivada das equações, foi observado valor máximo de 59,36 e $28,46 \mathrm{~cm}$ para perímetro do tórax e da perna, respectivamente; e ponto mínimo de $9,73 \mathrm{~cm}$ para largura da perna. Esses resultados diferem dos obtidos por Yañes et al. (2004), que encontraram coeficiente de determinação de 0,95 e 0,93 para equação de predição do perímetro da garupa e comprimento interno da carcaça em relação ao peso em jejum, respectivamente. Em seus estudos, Yañes et al. (2004) reportaram, em estudos com fêmeas Saanen, que o perímetro torácico foi a medida de maior correlação com peso em jejum e que pode ser utilizada para predizer o peso a partir de uma equação geral para todas as idades, o que neste estudo não ficou tão bem elucidado, já que, para os dados dos cinco grupamentos genéticos estudados, o coeficiente de determinação ficou em torno de 0,52 .

Tabela 5 - Equações de regressão de algumas características de carcaça de caprinos determinadas em relação ao peso em jejum

\begin{tabular}{llc}
\hline Característica & \multicolumn{1}{c}{ Equação } & $\mathrm{R}^{2}$ \\
\hline Peso de carcaça quente & $\mathrm{Y}=0,41 \mathrm{PJ}+7,82$ & 0,90 \\
Peso de carcaça fria & $\mathrm{y}=0,44 \mathrm{PJ}+8,33$ & 0,91 \\
Comprimento interno da carcaça & $\mathrm{y}=0,53 \mathrm{PJ}+43,93$ & 0,51 \\
Comprimento externo da carcaça & $\mathrm{y}=0,70 \mathrm{PJ}+48,34$ & 0,49 \\
Cobertura de gordura & $\mathrm{y}=0,032 \mathrm{PJ}+1,77$ & 0,02 \\
Conformação & $\mathrm{y}=0,075 \mathrm{PJ}+2,38$ & 0,24 \\
Perímetro da garupa & $\mathrm{y}=0,40 \mathrm{PJ}+37,81$ & 0,14 \\
Largura da garupa & $\mathrm{y}=0,16 \mathrm{PJ}+13,64$ & 0,15 \\
Perímetro do tórax & $\mathrm{y}=-0,0347 \mathrm{PJ}^{2}+0,59 \mathrm{PJ}+56,86$ & 0,52 \\
Perímetro da perna & $\mathrm{y}=-0,0452 \mathrm{PJ}^{2}+0,0728 \mathrm{PJ}+28,44$ & 0,13 \\
Largura da perna & $\mathrm{y}=0,0422 \mathrm{PJ}^{2}+1,276 \mathrm{PJ}+19,38$ & 0,65 \\
\hline
\end{tabular}

\section{Conclusões}

O cruzamento Boer $\times$ Alpino reduziu o comprimento de carcaça, aumentou a cobertura de gordura e a quantidade de tecidos depositados. A utilização das raças Boer e Anglo-Nubiana em cruzamentos com fêmeas
Alpinas ou mestiças Boer + Alpina resultou desempenho semelhante, confirmando que qualquer uma das raças pode ser utilizada em cruzamentos para terminação em confinamento. Carcaças de caprinos machos são maiores que as de fêmeas, contudo a quantidade de tecidos foi semelhante. 


\section{Referências}

ÁVILA, V.S. Crescimento e influencia do sexo sobre os componentes do peso vivo em ovinos. 1995. $206 \mathrm{f}$. Dissertação (Mestrado em Zootecnia) - Universidade Federal de Pelotas, Pelotas.

BONIFACINO, L.; KREMER, R.; ORLANDO, D. et al. Estúdio comparativo de corderos Corriedale y Corriedale x Texel. 2: pesos al nascer, ganâncias diárias y características de la carcasa. Revista Veterinária, v.70, p.63-71, 1979.

BUENO, M.S.; SANTOS, L.E.; CUNHA, E.A. et al. Avaliação de carcaças de cabritos abatidos com diferentes pesos vivos. Revista Nacional da Carne, n.273, p.72-79, 1999.

DEAMBRosis, P. Producción de carne ovina: crecimiento, producción y comercialización de carnes. (Colleción Nuestra Realidad, II). Montevideo: Universidad de la Republica, 1972. p.235-256.

DHANDA, J.S.; TAYLOR, D.G.; MCCOSKER, J.E. et al. The influence of goat genotype on the production of capreto and chevon carcasses. 1. Growth and carcass characteristics. Meat Science, v.52, p.355-361, 1999.

EL KHIDIR, I.A.; BABIKER, S.A.; SHAFIE, S.A. Comparative feedlot performance and carcass characteristics of Sudanese desert sheep and goats. Small Ruminant Research, v.30, p.147-151, 1998.

FREDERIKSEN, J.H. Design of crossbreeding trial. Animal Breeding Abstract, v.56, n.8, p.4-5, 1991.

GOONEWARDENE, L.A.; DAY, P.A.; PATRICK, N. et al. Preliminary evaluation of growth and carcass traits in Alpine and Boer crosses. Canadian Journal Animal Science, n.78, p.229-232, 1998.

JACOBS, J.A.; FIELD, R.A.; BOTKIN, M.P. et al. Effects of testosterone enanthate on lambs carcass composition and quality. Journal of Animal Science, v.34, n.1, p.30, 1972.

LLOYD, W.R.; SLYTER, A.L.; COSTELLO, W.J. Effects of breed, sex, and final weight on feedlot performance carcass characteristics and meat palatability of lambs. Journal of Animal Science, v.51, p.316-320, 1983.

MADRUGA, M.S. Carne caprina verdades e mitos à luz da ciência. Revista Nacional da Carne, v.23, n.264, p.34-40, 1999.

MALAN, S.W. The improved Boer goat. Small Ruminat Research, v.36, p.165-170, 2000 .

MENEZES, J.J.L. Desempenho e características de carcaça de caprinos e diferentes grupos raciais e idades de abate. 2005. 73f. Dissertação (Mestrado em Zootecnia) - Faculdade de Medicina Veterinária e Zootecnia, Universidade Estadual Paulista, Botucatu.
OSORIO, J.C.S. Estudio de la calidad de canales comercializadas en el tipo ternasco según la procedencia: bases para la mejora de dicha calidad en Brasil. 1992. 335f. Tese (Doutorado em Veterinária) - Universidad de Zaragoza, Zaragoza, 1992

PELLE, E.; PACSONI, V.; LAJOS, S. Results of crossing Ile de France with Merino sheep. Animal Breedding Abstract, v.55, p.866, 1987.

PIRES, C.C.; CARVALHO, S.; GRANDI, A. et al. Características quantitativas e composição tecidual da carcaça de cordeiros terminados em confinamento. Ciência Rural, v.29, n.3, p.539-543, 1999.

POTCHOIBA, M.J.; POTCHOIBA, C.D.; LU, F. et al. Effects off all-milk diet on weight gain, organ development, carcass characteristics and tissue composition, including fatty acids and cholesterol contents, of growing male goats. Small Ruminat Research, v.3, p.583-592, 1990.

SAÑUDO, C.; SIERRA, I. Calidad de la canal en la especie ovina. In: Ovino. Exclusivas ONE, España, p.127-153, 1986.

SIMELA, L.; NDLOVU, R.L.; SIBANDA, L.M. Carcass characteristics of the marketed goat from south-western. Small Ruminant Research, v.32, p.173-179, 1999.

SIQUEIRA, E.R.; FERNANDES, S. Pesos, rendimentos e perdas da carcaça de cordeiros Corriedale e mestiços Ile de France $x$ Corriedale, terminados em confinamento. Ciência Rural, v.29, n.1, p.143-148, 1999.

SKINNER, J.D. Utilization of the Boer goat for intensive animal production. Tropical Animal Production, v.4, p.120-128, 1972.

STANFORD, K.T.A.; MC ALLISTER, M.; MAC DOUGALL, et al. Use of ultra sound for the prediction of carcass characteristics in Alpine goats. Small Ruminant Research, v.15, p.195-201, 1995.

UNIVERSIDADE FEDERAL DE VIÇOSA - UFV. Sistemas de análise estatísticas e genéticas - SAEG. Versão 9.0. Viçosa, MG, 2000. 142p.

VAN NIEKERK, W.A.; CASEY, N.H. The Boer goat II. Growth, nutrient requirement, carcass and meat quality. Small Ruminant Research, v.1, p.355-368, 1988.

YAÑES, E.A. Desenvolvimento relativo dos tecidos e características de carcaça de cabritos Saanen, com diferentes pesos e níveis nutricionais. 2002. 132f. Tese (Doutorado em Zootecnia) - Faculdade de Ciências Agrárias e Veterinárias, Universidade Estadual Paulista, Jaboticabal.

YAÑES, E.A.; RESENDE, K.T.; FERREIRA, A.C.D. et al. Utilização de medidas biométricas para predizer características de carcaça de cabritos Saanen. Revista Brasileira de Zootecnia, v.33, n.6, p.1564-1572, 2004 . 